\title{
НОСТАЛЬГИЯ ПО ЛОГОСУ: ПОЭЗИЯ ИВАНА ЖДАНОВА В КОНТЕКСТЕ НЕОТРАДИЦИОНАЛИЗМА
}

\author{
NOSTALGIA FOR LOGOS: IVAN ZHDANOV'S POETRY \\ IN CONTEXT OF NEOTRADITIONALISM
}

\author{
EDYTA ANNA FEDORUSHKOV
}

\begin{abstract}
AвSTRACT. The paper aims at presenting an attempt to interpret Ivan Zhdanov's poetry in the context of neotraditionalism. This literary project, founded by Valery Tiupa, is based on the idea of dialogue by Mikhail Bakhtin as well as philosophy of personalism by Martin Buber, Nikolai Berdyaev, Emmanuel Levinas. In contrast to postmodernism, neotraditionalism takes an attempt to restore the value and esteem to widely understood cultural tradition (especially Mediterranean and Christian cultures).
\end{abstract}

Keywords: neotraditionalism, Ivan Zhdanov, contemporary poetry, Valery Tiupa, Mikhail Bakhtin, metarealism

Edyta Anna Fedorushkov, Uniwersytet im. Adama Mickiewicza w Poznaniu, Poznań Polska,wwwedka@gmail.com

ORCID ID: 0000-0002-4260-5409

Бытие современной художественной литературы, как можно полагать, все еще содержится под стражей указов, намеченных в основном французскими и американскими философами, филологами, литературоведами, сорганизовавшимися в конечном счете под общим названием постмодернизм. Предпринятая ими попытка освобождения литературы от пут ценностно-иерархической ориентации, выработанной многовековой традицией (и прежде всего уважительным отношением к ней), обернулась эстетическим диктатом внелитературной, на самом деле, практики. С тех пор попытки наметить аксиологическую ось художественного произведения зачастую встречаются с неодобрительным „взглядом” сверху, напоминающим об отсутствии какой-либо иерархии или ценностного центра.

Мощность постмодернистской „системности”, как ни парадоксально это звучит, можно измерить ее неоспоримым воздействием на русскую литературу с 1991 года. Навеянные Западом теории послужили общеупотребительной методологической матрицей для толкования отечественной литературы. Правда, сразу же раздались голоса о неадекват- 
ности данной парадигмы применительно к русской словесности, все же замечалось „лелеющее” отношение к постмодернизму, более или менее осознанно санкционированное хотя бы заглавиями репрезентативных учебников по современной русской литературе [см. Скоропанова 2001; Курицын 2001; Липовецкий 1997] или широкого спектра статей.

Rodzima twórczość - poza kilkoma, wciąż tymi samymi, nazwiskami - rzadko w przekonujący sposób dawała się interpretować zgodnie z regułami tej teorii [postmodernizmu - прим. E. F.]. Schemat większości artykułów sprowadzał się do prezentacji ogólnych założeń postmodernizmu i wymienienia kilku nazwisk lub utworów zaliczanych do tej kategorii, w najlepszym przypadku do opisu poszczególnych przedstawicieli tego nurtu. Lekturze towarzyszyło więc nieodparcie wrażenie, że teoretyczne dywagacje w niewielkim stopniu korespondują z rosyjską praktyką twórczą [Skotnicka 2001: 32].

Проведенная верификация данного культурного явления хоть и указала на резкие отличия русского постмодернизма от своего западного прототипа [см. Эпштейн 2005а], все-таки увязла, хотелось бы сказать, в корневище терминологической обречённости. Результатом стала зачастую сдержанная позиция критики относительно произнесения „конечного” или „своего” определения современной литературной активности. Примером такой научной сдержанности можно считать в данном случае более или менее, как можно полагать, рабочий термин „литература другая". Нельзя не заметить, что крайняя неопределённость примененного названия выявляет однако его сугубо постмодернистскую природу. Вездесущность и беспредельная универсальность постмодернизма объясняется его новаторской формулой: данное явление, терминологически восходя к постмодерну как большой исторической эпохе и, следовательно, наследуя поневоле все его параметры, определяет состояние общества и культуры вообще и не ограничивается новым стилем творчества или теоретической системой [см. Lyotard 1997; Эпштейн 2005a: 14; Słownik socjologii i nauk społecznych 2004]. Всеобъемлющее бытие постмодернизма требует тогда аналогичной системы, базирующейся на соответственно расширенной концепции, следовательно, выходящей за рамки узких литературных явлений, таких как течение, движение или школа.

Альтернативой постмодернизму, постулирующему критическое и скептическое раздумье надо всем прошлым, можно признать выросший на почве русского литературоведения неотрадиционализм. Автором проекта следует считать Валерия Тюпу, хотя он не является его основоположником. Российский ученый систематизирует, главным образом, традиционалистские концепции, руководящие творческими поисками 
акмеистов, идеи диалогизма Михаила Бахтина и персонализма Николая Бердяева, Мартина Бубера, Эммануела Левинаса, схемы творческого сознания Сергея Аверинцева и др. В центр данного замысла Тюпа ставит идею диалога, являющуюся своеобразным связующим звеном между двумя составляющими проекта: „нео” - тем, что новое - и „традиции”, базирующейся на веками утвержденной эллинско-христианской системе ценностей. Исторической почвой для традиционалистского сознания ученый считает время античности и средневековья, осуществляющее каноничный и конвенциональный подход к художественному произведению. Революционным подходом к вопросу о возродившемся традиционализме в XX столетии стала, по мнению Тюпы, идея свободного, непринужденного обращения к многовековому культурному наследию. Подоплекой такого обращения стала, в свою очередь, упомянутая нами выше многофункциональная категория „диалога”, отвечающая как за актуальность традиционного по идее художественного образа, так и за его соответствующее восприятие в пределах так называемых „конвергентных" (сближающихся) сознаний (автора-героя-читателя).

Утверждая гармонию сосуществования пары мнимых антонимов „нео” и „традиции” Тюпа цитирует одного из поклонников такого миропонимания, Томаса Стернза Элиота: „Прошлое в такой же мере корректируется настоящим, в какой настоящее направляется прошлым" [Элиот 1987: 171].

Взаимосвязь прошлого (традиции) и настоящего (новаторства) образует, по мнению одного из исследователей неотрадиционализма Олега Склярова, динамическую концепцию традиции [Скляров 2015: 68], в которой „память, - как пишет Вячеслав Иванов, - начало динамическое” [Иванов 1979: 386]. Неотрадиционализм, таким образом, отмежёвывается как от игрового скептического подхода к традиции постмодернизма, так и от статического отношения к традиции пассеистов, утверждающих прошлый порядок мира законченным и совершенным. Своеобразная взаимообращенность прошлого и настоящего выводит понимание традиции за скобки одновекторной направленности истории. Точкой отсчёта для неотрадиционализма является тогда „смысл”, „логос", не укорененный в определенном историческом отрезке времени, а представляющий собой результат „процесса ценностно-смысловой преемственности культурного творчества" [Скляров 2015: 117] и в его, процесса, пределах всегда актуализирующийся заново.

Такая модель традиционалистского творческого сознания совпадает на наш взгляд с мировоззренческой ориентацией современного алтайского поэта Ивана Жданова. Своеобразной поэтической декларацией следует считать предисловие к книге с весьма сугтестивным названием 
Диалог-комментарий пятнадияати стихотворений Ивана Жданова, написанной в соавторстве с Марком Шатуновским. Как пишет поэт,

культура - представительство той системы ценностей, которая заложена в данном обществе, в данных исторических обстоятельствах. Культура - это, вообще-то говоря, выращивание, по первоначальному значению этого слова. А что выращивается в наше время? Вот то и выращивается в соответствии с той системой ценностей, которая сейчас возможна. Вышедшая из посттоталитарного подвала, бледная, как картофельный росток, который не ведает, суждено ли ему когда-нибудь попасть в почву. Такая культура ущербна, и в этом ее специфичность. Преодоление этой специфичности стоит все дороже. ...Но почему преодоление все-таки необходимо? Потому что житейски ты - один, а бытийственно - совсем другой [Жданов 1998: 7].

В вышеприведенном фрагменте можно проследить отчетливые параллели между осмыслением культуры алтайским поэтом и ее неотрадиционалистской трактовкой. Знаменательно, что сущность культуры Жданов рассматривает сквозь призму ее современного, по его убеждению, ущербного состояния. Главным дефектом современной культуры автор сборника Портрет считает ее беспочвенность, проявляющуюся в зыбкой, не укорененной системе ценностей, актуальной для нынешней цивилизации.

Симптоматично в этом плане то, что Жданов различает две стороны человеческого существования: житейскую и бытийственную. „Житейская" как внешняя, если так можно выразиться, „подённая" сторона человеческой жизни является знаменем современной беспочвенности культуры, ориентированной на акцидентальность и случайность миропорядка. Бытийственность, в свою очередь, характеризует другой способ существования. Михаил Эпштейн, разъясняя значение слова „бытийственность”, обращается к его исходному первообразу - глаголу „быть”, который впоследствии наращивается или, вернее, восполняется суффиксами [Эпштейн 2005б]. Поскольку исходное „быть” несамодостаточно и всегда требует конкретного и поэтому ограниченного временем и пространством субъекта действия (в широком, не только грамматическом, смысле) постольку развернутое понятие „бытийственность” уже содержит в себе „вес" бытия, коннотируя не только физическую, но, прежде всего, духовную (метафизическую), следовательно, не ограниченную временем и пространством сущность бытия.

Бытийственность и житейскость на первый взгляд можно признать синонимами „памяти” и „беспамятства”, которые всегда противостоят друг другу. В такой концептуализации „память” понимается как возможность сохранять, накапливать и воспроизводить то, что единично, акцидентально и закрыто в конкретном времени-пространстве. Беспа- 
мятство, в свою очередь, не обладает такими способностями, оно всегда „заключено” в том, что здесь и сейчас. Однако бытийственность как другой способ существования может достичь полноты самосознания лишь при осмыслении предельности своей „житейскости”. Иными словами, достижение беспамятства (отмена всего, что в человеческой жизни представляет собой опыт и смысл прошлого) должно в конечном счете привести к возрождению памяти. В переводе на материю художественного произведения такой двойной способ существования будет относиться несомненно к слову. В такой концептуализации „бытийственность” слова должна основываться на его прочном, непоколебимом, фундаменте - смысле, укрепленном и признанном многовековой культурой. Замечательно, что традиционализм обращается к слову как к последнему, наиболее полному средоточию жизни, признавая его превосходство над акцидентальными фактами жизни [Скляров 2015: 89]. Слово в таком понимании приобретает онтологический статус универсальной надысторической единицы - Логоса. Тоску или, вернее, ностальгию по Слову-Логосу выражает с нашей точки зрения именно послание Ивана Жданова. Ключ к его восстановлению и повторному к нему причащению можно отыскать в последних предложениях предисловия:

Ясно, что современность наша равно удалена как от золотого века, так и от библейской гармонии. Отсутствие культурного контекста, а точнее, его ублюдочное состояние может и занять место почвы конкретного произведения. Тогда произведение вынуждено само строить себе подходящую почву. В этом-то и смысл данного диалога-комментария [Жданов 1998: 7].

Можно заметить, что поэт не пренебрегает искалеченным и равнодушным характером современной культуры. Принимая во внимание временное увечье культуры и пострадавшего от этого человечества, он пытается найти путь к их восстановлению а, вернее - возрождению. Точкой отсчета является для поэта кризисное состояние личности, отделившейся от своих ценностно-культурных корней. В стихотворении Взгляд читаем:

Там нет меня. Над горизонтом слова взойдут деревья и к нему примерзнут я никогда их не смогу догнать.

[Жданов 2005: 27]

Ощущение одиночества и дезинтеграции с мирозданием можно считать следствием пережитого человеком обесценивания слова. Оторванность от его смыслотворческой почвы оборачивается отстранением личности от гармонического сосуществования во вселенной. Девальвация 
слова приводит к его профанации так, как это происходит в стихотворении Неоновый калейдоскоп:

Вот и слово прошло по прокатному стану неона,

Сквозь двумерную смерть и застыло багровой короной

Над пустым магазином, над потным челом мирозданья,

Нашатырной тоской проникая в потемки молчанья.

[Жданов 2005: 87]

Слово тут, низведенное человеком к двухмерной плоскости, утрачивает свое логосное значение и замирает в информационной надписи. Результатом такого обращения со словом становится опустошение и, если так можно выразиться, обезлюдение мироздания, погрузившемуся в молчание. Дискредитация слова - это и потеря орудия контакта с другим человеком. В другом стихотворении поэта читаем:

Душа идет на нет, и небо убывает,

и вот уже меж звезд зажата пятерня.

O, как стряхнуть бы их! Меня никто не знает.

Меня как будто нет. Никто не ждет меня.

[Жданов 2005: 27]

Отчуждение личности от мироздания равно отчуждению от самого себя. Замечательно, что лирический субъект в стихотворениях Жданова зачастую выражает себя через самоотстранение от пространства событий. Тем не менее, следует заметить, что данная манифестация в рамках его сознания обусловлена некоторой реакцией извне. Чувство самоотчуждения усугубляется по мере отдаления от другой личности и, следовательно, свершившегося разрыва связи с другим человеком. В стихотворении Ты, смерть, красна не на миру читаем:

И в смертном шепоте моем не уцелело

Ни слов для совести моей, ни берегов для рек.

[Жданов 2005: 58]

Интересно обратиться к трактовке идеи совести, данной поэтом. Как пишет Жданов,

со-весть, весть совместная с кем? С кем в первостепенную очередь, если не с Богом? Твоего бессмертного с твоим абсолютным собеседником. Твоей души с ее Создателем [Жданов 2005: 42].

Можно заметить, что даже такое индивидуальное и интимное явление, как совесть, требует отнесения к кому-то, разделения вести с кем-то, об- 
ращенности к „другому” в данном случае к Абсолюту - Богу. Подобной трактовки требует сфера выражения чувств: „Люблю, боюсь, зачем, кого - слова подобны краже" [Жданов 2005: 58].

Значение слов „люблю, боюсь” улетучивается по мере невозможности определения их направления, цели. Залогом повторного восстановления слова является, таким образом, обращение к „другому”, как к той точке отсчета, благодаря которой будет возможным восстановление „я" лирического субъекта. Как пишет Тюпа,

по известному замечанию М. Бахтина, положившего начало разработке эстетики неотрадиционализма, „я не могу стать самим собой без другого; я должен найти себя в другом, найдя другого в себе" [Тюпа 1992: 92].

Следует отметить, что куда более широкое понятие „Другого” в постмодернистской эстетике можно соотнести с понятиями „цитаты”, , реминисценции" или „интертекстуальности”, имеющей свойство „приобретенности", „,заимствования" или, грубо говоря, осознанного игрового „варваризма”, „слова подобного краже”. В эстетике неотрадиционализма понятие „Другой” получает смысл врожденной и природной основы художественного творчества. Поэтому аффирмация собственного „я", а также возрождение полноценного слова, может произойти лишь при условии признания автономной сферы лирического „я" сферой пребывания „другого”. Нагляднее всего это показано в стихотворении Расстояние между тобою и мной - это и есть ты:

Словно ты повторяешь мой жест, обращенный к тебе,

Так в бессмертном полете безвестная птица крылом

Ловит большее сердце, своей подчиняясь судьбе,

И становится небом, но не растворяется в нем.

Да, я связан с тобой расстоянием - и это закон,

Разрешающий ревность как правду и волю твою.

Я бессмертен пока я покорен, но не покорён,

Потому что люблю, потому что люблю, потому что люблю.

[Жданов 2005: 99]

Расстояние в данном случае не коннотирует отделения а является сферой причащения, местом повторного установления связи с „другим" и, одновременно, обретения бессмертия. Существенным условием на пути к личностной реконструкции лирического „я" является покорность, дефинирующая омонимически обыгрываемую здесь непокорённость. Покорность лирического субъекта и является смирением перед „Другим", а следовательно и перед целым мирозданием, выражается уважительным, не игровым отношением к ним. Позицию смирения 
лирического субъекта или, другими словами, русского понимания „малодушия" следует считать, пользуясь словами Тюпы, выражением „ответственности перед объективностью бытия” [Тюпа 2005: 95]. Как пишет ученый,

в основе неотрадиционалистского служения феномену художественности угадывается философия конвергенции между субъектом и объектом. [...] Они нерасторжимы, поскольку оба нуждаются один в другом для взаимной актуализации [Тюпа 2005: 95].

Восстановление лирического „я" путем аффирмации „Другого” восстанавливает утраченную ценность слова „люблю”.

Наиболее упорную борьбу за слово Жданов выразил в стихотворении До слова:

Ты - сцена и актер в пустующем театре.

Ты занавес сорвешь, разыгрывая быт,

И пьяная тоска, горящая, как натрий,

В кромешной темноте по залу пролетит.

Тряпичные сады задушены плодами,

Когда твою гортань перегибает речь

И жестяной погром тебя возносит в драме

Высвечивать углы, разбойничать и жечь.

Но утлые гробы незаселенных кресел

Не дрогнут, не вздохнут, не хрястнут пополам,

Не двинутся туда, где ты опять развесил

Крапленый кавардак, побитый молью хлам.

[Жданов 2005: 77]

Начальные строки произведения являются иллюстрацией театрализованного быта, „житейскости”, носящей характер шумного балагана и глухой пустоты. Слово подменено здесь криком или визгом, невыносимым для того, кто его издает, но, одновременно, оно неслышно для окружающих. Это скорее пустой звук, утративший свое значение и безотчетно блуждающий в немом пространстве инсценированного быта:

И, с этой немотой поддерживая ссору,

Свой вечный монолог ты катишь, как Сизиф.

[Жданов 2005: 77]

Безотчетность слова является для его выразителя своеобразным заключением, так как не дает освобождения (ср. утверждение Ролана Барта: „Свобода, возможна только вне языка”) а как раз наоборот, обрекает на бесконечный бег за словом, следовательно, за тем, кто данное слово примет: 
Но где-то в стороне от взгляда ледяного,

Свивая в смерч твою горчичную тюрьму,

Рождается впотьмах само собою слово

И тянется к тебе, и ты идешь к нему.

[Жданов 2005: 78]

Преодоление немоты и приобщение к слову кратковременно и принимает в стихотворении образ снящегося озарения. Слово тут уже не подчинено бытовому порядку мира, а обретает независимый от него смысл, так как приходит извне житейского „балагана-театра”. Обнаруженные в стихотворении две перспективы слова соответствуют антиномии „игры” и „откровения", служащей характеристикой поочередно авангардистской (в дальнейшем - постмодернистской) и традиционалистской парадигм в трактовке Тюпы [Тюпа 2005: 92]. Откровение, как утверждает ученый, „особая форма знания, приобретаемая душевным трудом" и ориентирована на постижение высшего, трансцендентного смысла [Тюпа 2005: 92-93]. Слово, таким образом, становится Логосом или, вернее, возрождается и возвращается в своей логосной основе. Следует обратить внимание на то, что понимание Логоса не ограничивается лишь его животворным, вызывающим к жизни аспектом. Логос как принцип, который определяет смысл каждой вещи, целеустремлен, не задерживается на познании, а содержит в себе стимул к действию [Reale 1999: 392]. Встреча со словом-Логосом изменяет также облик лирического „ты”, приобретающего в конечном счете статус лирического „я":

О, дайте только крест! И я вздохну от боли,

И продолжая дно, и берега креня.

Я брошу балаган - и там в открытом поле...

Но кто-то видит сон, и сон длинней меня.

[Жданов 2005:78]

Несомненно, оценка Сизифова труда лирического героя принадлежит читателю, так как его активного присутствия лирическое "я" и ожидает („о, дайте только крест!”). Стремление к слову-Логосу во время обесценивания слова, скептического и иронического отношения к нему является тем более сложным заданием. Однако уже чувство ностальгии по нему, переживаемой боли следует считать залогом свершившейся перемены.

\section{Библиография}

Жданов И. 2005. Воздух и ветер. Сочинения и фотографии, Москва: Наука.

Жданов И., Шатуновский М. 1997. Диалог-комментарий двенадизати стихотворений Ивана Жданова, Москва: Издательство Университета истории культур. 
Иванов В., Гершензон М. 1979. Переписка из двух углов, Брюссель: Foyer Oriental Chrétien. Курицын Вяч. 2001. Русский литературный постмодернизм, Москва: ОГИ.

Липовецкий М. 1997. Русский постмодернизм, Екатеринбург: Уральский государственный педагогический университет.

Скляров О. 2014. Неотрадиционализм В русской литературе XX века: философско-эстетические интенции и художественные стратегии, диссертация на соискание ученой степени доктора филологических наук, Москва.

Скоропанова И. 2001. Русская постмодернистская литература, Москва: Наука, Флинта.

Тюпа В. 1992. Поляризащия литературного сознания, [в:] G. Bobilewicz-Bryś (ред.), Literatura rosyjska XX wieku. Nowe czasy, nowe problemy, Warszawa: Omnitech Press.

Элиот Т.-С. 1987. Традиция и индивидуальный талант, [в:] Г. Косиков (ред.), Зарубежная эстетика и теория литературы XIX-XX вb., Москва: Издательство МГУ.

Эпштейн М. 2005а. Постмодерн в русской литературе, Москва: Высшая школа.

Эпштейн М. 2005б. Слово и молчание в русской культуре, электронный ресурс: http:/ / magazines.russ.ru/zvezda/2005/10/ep12.html (доступ 2.01.2019)

Lyotard J.-F. 1997. Kondycja ponowoczesna. Raport o stanie wiedzy, przeł. M. Kowalska, J. Migasiński, Warszawa: Aletheia.

Marshall G. (ред.). 2004. Stownik socjologii i nauk społecznych, Warszawa: Wydawnictwo Naukowe PWN.

Reale G. 1999. Historia filozofii starożytnej, т. 3, Lublin: Wydawnictwo KUL.

Skotnicka A. 2001. Model prozy „innej” w literaturze rosyjskiej po 1985 roku, Wrocław: Wydawnictwo Uniwersytetu Wrocławskiego. 